\title{
"COMO TRABALHAM OS CIENTISTAS?" POTENCIALIDADES DE UMA ATIVIDADE DE ESCRITA PARA A DISCUSSÃO ACERCA DA NATUREZA DA CIÊNCIA NAS AULAS DE CIÊNCIAS*
}

\section{"How scientists work?" Potentialities of a written activity for a discussion about the nature of science in science class}

\author{
Cláudia Faria ${ }^{1}$ Sofia Freire ${ }^{2}$. Cecília Galvão ${ }^{3}$. \\ Pedro Reis ${ }^{4}$. Orlando Figueiredo ${ }^{5}$
}

\begin{abstract}
Resumo: Vários estudos em educação têm salientado a natureza da ciência como sendo uma componente importante da educação em ciência. Neste trabalho, é apresentada uma atividade de escrita e discussão de histórias imaginadas sobre cientistas, e são discutidas as suas potencialidades para a exploração das ideias dos alunos sobre a atividade científica. Os dados foram recolhidos através de entrevistas com professores e alunos. Foi também efetuada a análise de documentos escritos e a observação das sessões de discussão. Os resultados revelaram a presença, nos alunos, de ideias inadequadas acerca do que é a atividade científica. Revelaram, também, dificuldades por parte dos professores na gestão da discussão e no confronto dessas ideias, que dificultam a compreensão acerca da natureza do conhecimento científico. É sugerido que esta atividade possa ser enriquecida pela sua integração num contexto real, que facilite o estabelecimento de conexões com o trabalho de cientistas reais.
\end{abstract}

Palavras-chave: Educação em ciência. Ensino de ciências. Natureza da ciência. Cientistas. Ficção.

\begin{abstract}
Many educational studies stress that knowledge about the nature of science should be an important component of science education. In this paper we present and discuss the potentiality of an activity of writing and discussing fictional stories about scientists to explore with students their main ideas about scientific activity. Data were collected by way of interviews with teachers and with students. Written documents were analyzed and naturalistic observation of discussion sessions was carried on. The results reveal that students have some distorted ideas of science and scientific activity. They also reveal teachers' difficulties with the organization of the discussion and the confrontation of students' ideas, which may prevent students from developing an understanding about the nature of scientific knowledge. Considering these difficulties, we suggest that this type of activity could be enriched by being integrated in a more real context, where students are encouraged to make connections to the work of real scientists.
\end{abstract}

Keywords: Science education. Nature of science. Science teaching. Science fictional stories.

\footnotetext{
* Parte deste estudo foi financiado pela Comissão Europeia ( $\left.6^{\circ} \mathrm{FWP}\right)$, como sendo parte de um projeto Europeu Popularity and Relevance of Science Education for Scientific Literacy (PARSEL).

${ }^{1}$ Universidade de Lisboa, Instituto de Educação, Alameda da Universidade, Lisboa, 1649-013 Lisboa, Portugal. E-mail: cbfaria@ie.ul.pt

2,3,4,5 Universidade de Lisboa, Instituto de Educação, Lisboa, Portugal.
} 


\section{Introdução}

Nas últimas décadas, diversas reformas dos currículos de ciências têm tido como uma das suas finalidades melhorar o conhecimento dos alunos acerca da natureza da ciência (NC) (LEDERMAN, 2006). Atualmente, considera-se que, para ser um cidadão literato, é necessário não só compreender uma série de factos e leis da ciência, como, também, ter conhecimentos sobre o modo como o conhecimento científico é construído, e, ainda, sobre a natureza desse mesmo conhecimento (SCHWARTZ; LEDERMAN; CRAWFORD, 2004). Só este conhecimento complexo e amplo poderá permitir, não só que os alunos compreendam de forma mais significativa os conteúdos científicos (conhecimento substantivo), como, também, que consigam tomar decisões sobre assuntos que envolvem a ciência, de uma forma mais informada e fundamentada (DRIVER et al., 1996; SCHWARTZ; LEDERMAN; CRAWFORD, 2004). De acordo com Driver e colaboradores (1996), há três aspetos essenciais que, numa perspetiva da compreensão pública da ciência, os alunos devem compreender de forma aprofundada: as finalidades do trabalho científico, a natureza do conhecimento científico e a ideia de que a ciência é um empreendimento social. Com efeito, sem uma compreensão aprofundada de como o conhecimento científico é construído, e acerca das caraterísticas únicas da ciência, é difícil, ao cidadão comum (e ao aluno), apreciar diferentes asserções, analisar criticamente os limites e as potencialidades de cada uma delas, enquadrar as questões científicas polémicas, compreender a não-universalidade das propostas científicas, bem como o seu caráter conjuntural e modificável, e situá-las num contexto social, ético e político mais amplo, que lhes permita tomar decisões informadas (DRIVER et al., 1996; LEDERMAN, 2006; O’NEIL; POLMAN, 2004; PRAIA; GIL-PÉREZ; VILCHES, 2007). Torna-se assim essencial, como há já muito é reconhecido, incluir esta dimensão nos currículos de ciências.

Mas, como integrar estes aspetos no currículo e como abordá-los do ponto de vista pedagógico? As abordagens pedagógicas utilizadas para alargar ou modificar a visão dos alunos acerca da NC podem ser classificadas como sendo de natureza explícita ou implícita (KHISHFE; ABD-EL-KHALICK, 2002). Nas últimas décadas, a ideia de desenvolver uma abordagem explícita da natureza da ciência tem ganho força, em face de estudos que apontam que as abordagens implícitas não são eficientes, ou seja, que a simples imersão em atividades investigativas ou a mera discussão e análise sobre a história da ciência não é suficiente para que os alunos desenvolvam um conhecimento acerca da natureza do conhecimento, que eles próprios estão a construir (AKERSON; ABD-EL-KHALICK, 2005; DUSCHL, 2006). Assim, considera-se que a NC tem de ser abordada de uma forma explícita e que, para tal, esta deve ser reconhecida como um objetivo a atingir, i.e., deve ser reconhecida como um conteúdo que é necessário que os alunos apropriem, o que implica definir estratégias e criar contextos específicos de aprendizagem (AKERSON; VOLRICH, 2006; SCHWARTZ; LEDERMAN; CRAWFORD, 2004). Nos últimos anos, foi ainda acrescentada uma dimensão reflexiva a estas abordagens, que procura promover a conexão das atividades realizadas com o trabalho de cientistas e de favorecer algumas generalizações acerca da epistemologia da ciência. Mais importante do que abordar aspetos da NC num âmbito de um tema específico de ciência, é discutir estes aspetos de forma explícita e reflexiva (KHISHFE; ABD-EL-KHALICK, 2002). Praia, Gil-Pérez e Vilches (2007, p. 152) acrescentam ainda que a clarificação sobre a NC é fundamental, se "essa clarificação não se limitar a uma mera exposição verbal de determinadas

Ciênc. Educ., Bauru, v. 20, n. 1, p. 1-22, 2014 
características, mas abrir caminho a uma autêntica imersão numa cultura científica e tecnológica". No mesmo sentido, Teixeira, Freire Jr. e El-Hani (2009) desenvolveram uma abordagem da NC histórica e filosoficamente contextualizada junto de alunos de um curso de Física, tendo observado que:

[...] a despeito da existência de um foco de resistência à mudança, caracterizado pela presença, no pós-teste, de concepções empírico-indutivistas, parece ter havido, de um modo geral, um amadurecimento na compreensão dos estudantes que participaram da pesquisa acerca dos aspectos da natureza da ciência abordados, visto que apareceram, no final: maior diversificação nas visões sobre métodos científicos e sobre o papel do experimento na ciência; superação significativa da visão realista ingênua; maior entendimento acerca da natureza conjectural da ciência e da influência de fatores sociais na produção científica. (TEIXEIRA; FREIRE JR.; EL-HANI, 2009, p. 548)

A criação pelos alunos de histórias imaginadas acerca dos cientistas e do seu trabalho e a discussão em sala de aula das ideias e imagens presentes nessas histórias, poderão ser, igualmente, estratégia adequada e efetiva, que permita aos alunos clarificarem, confrontarem e aprofundarem o seu conhecimento acerca da NC (REIS; GALVÃO, 2007). Alguns estudos centrados na análise deste tipo de atividades (REIS; GALVÃO, 2006; REIS; RODRIGUES; SANTOS, 2006; REIS; GALVÃO, 2007) revelaram que a escrita destas histórias poderá ser importante, não só para a identificação das visões estereotipadas que os alunos têm dos cientistas, da ciência e da atividade científica, como, também, quando esta é seguida por uma situação de entrevista, através da qual os alunos são confrontados com as suas próprias imagens e ideias, pode-se constituir como um veículo eficaz na mudança, reformulação e/ou expansão dessas mesmas visões (REIS; GALVÃO, 2007).

De acordo com Reis e Galvão (2006), um aspeto importante a ter em conta, no entanto, é que, sendo estas histórias imaginadas, a análise dos seus enredos não proporciona um retrato direto e nítido das conceções e imagens que os alunos têm acerca dos cientistas, da ciência e da atividade científica. Pelo contrário, os enredos destas histórias estão recheados de uma série de outros elementos, nomeadamente: a) ideias e sentimentos dos alunos acerca da ciência; b) valores dos alunos; c) imagens provenientes dos meios de comunicação social, de filmes e de livros de ficção científica (ex. MAT'THEWS; DAVIES, 1999); d) representações sociais relativamente aos cientistas e à atividade científica; e e) conjunto de elementos que os alunos identificam como parte integrante de uma boa história de ficção. Não obstante estes limites, as histórias dos alunos podem funcionar como um ponto de partida ou como um contexto facilitador da discussão sobre diferentes aspetos, permitindo distinguir os elementos que correspondem a pensamentos reais sobre a ciência e os cientistas, de outros elementos simplesmente ficcionados (REIS; GALVÃO, 2006) e, eventualmente, modificar ou reformular essas conceções e imagens.

Diversos autores têm refletido sobre as potencialidades pedagógicas da discussão em sala de aula (DAY; BRYCE, 2011; OSBORNE; ERDURAN; SIMON, 2004; SADLER; ZEIDLER, 2005; SIMON; ERDURAN; OSBORNE, 2006). A escolha da discussão como veícu- 
Faria, C. et al.

lo de aprendizagem assenta em diferentes dimensões. Em primeiro lugar, não só a discussão pode ser entendida, segundo palavras de Parker e Hess (2001, p. 273, tradução nossa), "tanto como uma forma de aprender como uma forma de estar com o outro", como, também, a dimensão discursiva é um elemento central na construção do conhecimento científico e, logo, aprender para e através da discussão (PARKER; HESS, 2001) pode ser um objetivo pedagógico central na educação em ciência (DAWSON; VENVILLE, 2010). Para além disso, quando a discussão funciona como uma inquirição partilhada sobre um determinado objeto de conhecimento, permite que os alunos envolvidos desenvolvam uma compreensão mais aprofundada e um melhor conhecimento do objeto em discussão (PARKER; HESS, 2001). Com efeito, o confronto com um ponto de vista distinto do seu, obriga o sujeito a compreender as ideias do outro para defender as suas, obriga-o a argumentar para defender o seu ponto de vista e a gerir a interação estabelecida (quem lidera? quando há consenso? do que tenho de abdicar? e quando?...). Este processo de construção de um espaço intersubjetivo facilita, segundo Doise, Mugny e Perret-Clermont (1975), a reelaboração de saberes e de raciocínios, promovendo o desenvolvimento cognitivo e a aprendizagem. Finalmente, e tal como afirmam Duschl e Grandy (2008), é importante desenvolver atividades que tornem o pensamento visível, permitindo aos professores identificar não só o modo de raciocinar e as formas de argumentar, como, também, as suas ideias, e dar feedback significativo aos alunos.

Assim, partilhar e discutir histórias imaginadas num contexto de sala de aula pode criar condições para que os alunos conheçam outras interpretações e experiências de vida, facilitando a expansão da compreensão individual acerca da ciência e da atividade científica, assim como potenciar a discussão de inúmeros aspetos processuais, políticos, sociais, ambientais e éticos inerentes à ciência atual (REIS; GALVÃO, 2004, 2007). No entanto, introduzir uma discussão reflexiva na sala de aula requer, da parte do professor, um leque de estratégias pedagógicas para iniciar e dar suporte à argumentação, para orquestrar a discussão, de forma a que as diferentes visões sejam explicadas, comparadas e contrastadas, e para facilitar a decisão sobre que posições oferecem a melhor interpretação (SIMON; ERDURAN; OSBORNE, 2006).

Tendo em conta as considerações feitas, torna-se extremamente pertinente compreender como este tipo de atividades pode ser implementado no contexto de sala de aula com o objetivo de promover uma compreensão funcional (LEDERMAN, 2006) acerca da NC. Com este artigo, pretendemos explorar uma atividade de escrita e discussão sobre os cientistas e a ciência, refletindo acerca das suas potencialidades e constrangimentos envolvidos na identificação das ideias dos alunos acerca da natureza da atividade científica e na sua exploração em sala de aula. 


\section{Metodologia}

A atividade analisada neste trabalho foi desenvolvida e implementada no âmbito de um projeto, Popularity and Relevance of Science Education for Science Literacy (PARSEL) ${ }^{6}$ cujo principal objetivo foi o de desenvolver e implementar materiais curriculares de ciência inovadores. Este projeto também pretendeu facilitar o desenvolvimento profissional dos professores envolvidos na sua implementação. Nesse sentido, os professores foram encorajados a participar na implementação das atividades de uma forma ativa, a avaliá-las e a apropriaremnas, modificando-as de acordo com as necessidades e os contextos de sala de aula.

Com o objetivo de refletir sobre as potencialidades e constrangimentos desta atividade de escrita e discussão na sala de aula, acompanhamos três professores e os seus respetivos alunos, ao longo do processo de implementação, assumindo uma abordagem interpretativa (Erickson, 1986). De acordo com Erickson (1986, p. 119, tradução nossa), uma abordagem interpretativa diz respeito à procura de "um sentido imediato e local para as ações, tal como definido pelo ponto de vista dos seus atores", sendo, como tal, útil quando o objetivo da investigação é o de descrever, como é o caso, o modo como foi implementada uma atividade, e o modo como alunos e professores a vivenciaram. Neste trabalho, foram analisadas as histórias produzidas pelos alunos, tendo sido alguns questionados com o objetivo de compreender o modo como desenvolveram a atividade, e os professores foram também inquiridos para compreendermos quais as vantagens e quais as dificuldades que encontraram na implementação da atividade.

\section{Participantes}

Neste estudo, participou um grupo de 47 alunos portugueses, de duas turmas diferentes. Uma turma do $9^{\circ}$ ano de escolaridade (28 alunos, dos quais 15 raparigas) e uma turma do $11^{\circ}$ ano de escolaridade, da área científica (19 alunos, dos quais dez raparigas). No sistema de ensino Português, o $9^{\circ}$ ano corresponde ao último ano do Ensino Básico, durante o qual os alunos ainda não escolheram um ramo de estudos específico, focando-se o currículo das ciências em aspetos mais gerais da ciência (ciências naturais), contrariamente ao $11^{\circ}$ ano, que corresponde ao segundo ano do ensino secundário, no qual os alunos já enveredaram por um ramo de estudos específico. No caso deste estudo, os alunos envolvidos pertenciam ao ramo científico das ciências físicas e naturais (ex. biologia, geologia). É ainda de mencionar que o currículo das ciências Português refere de forma explícita que a compreensão acerca da NC constitui um dos objetivos da educação em ciência no Ensino Básico e secundário (PORTUGAL, 2001, 2003). Os alunos eram provenientes de duas escolas diferentes, uma privada (turma do $9^{\circ}$ ano) e uma pública (turma do $11^{\circ}$ ano). A atividade foi implementada na disciplina de ciências naturais (no caso da turma do $9^{\circ}$ ano) e nas disciplinas de biologia e de filosofia (no caso da turma do $11^{\circ}$ ano).

${ }^{6}$ Disponível em: <http://www.parsel.uni-kiel.de/cms/>. Acesso em: 31 jan. 2014. 
Para além disso, participaram, neste estudo, três professores, um que trabalhou com o $9^{\circ}$ ano, e dois que trabalharam, colaborativamente, com o $11^{\circ}$ ano. $\mathrm{O}$ professor do $9^{\circ}$ ano tinha uma licenciatura em Biologia/Geologia, um dos professores do $11^{\circ}$ ano tinha uma licenciatura em Biologia, e o outro professor do $11^{\circ}$ ano, uma licenciatura em Filosofia. Neste caso, estes dois professores já trabalhavam regularmente em colaboração.

\section{Descrição e implementação da atividade}

A atividade proposta inclui diversas etapas. Numa primeira fase, é pedido a cada aluno que escreva, individualmente, uma história ficcionada que envolva o trabalho de um grupo de cientistas, relacionado com uma questão científica controversa e real. É efetuada uma referência explícita ao envolvimento de um grupo de cientistas, para assegurar a possibilidade de se obterem informações acerca da visão do aluno sobre as relações dentro da comunidade científica. Numa segunda fase, os alunos analisam em grupo uma das histórias escritas pela turma, tendo em atenção diversos aspetos, tais como: as caraterísticas dos cientistas envolvidos (cognitivas, socioafetivas, éticas), as caraterísticas da atividade científica descrita (objetivos, locais onde ocorre, métodos e instrumentos de pesquisa, relações entre os cientistas) e as interações entre ciência, tecnologia e sociedade (o impacto da ciência e da tecnologia, o controlo realizado pela sociedade). Finalmente, os alunos leem a história a toda a turma e organizam uma sessão de discussão sobre as caraterísticas da atividade científica presentes na história analisada.

$\mathrm{Na}$ implementação da atividade, cada professor seguiu uma abordagem um pouco diferente. No caso do $9^{\circ}$ ano, o professor solicitou, aos alunos, que escrevessem a história como trabalho de casa (tiveram 15 dias para a realização da tarefa). Após este período, o professor analisou todas as histórias escritas, tendo em atenção as ideias que estas transmitiam acerca das caraterísticas dos cientistas, da atividade científica e das interações ciência, tecnologia e sociedade. Com base nesta análise, o professor selecionou uma, e apenas uma, das histórias, que apresentava um grande número de ideias preconcebidas acerca destas temáticas, para ser discutida por toda a turma, em sala de aula.

No caso do $11^{\circ}$ ano, os alunos escreveram também a história como trabalho de casa. Após duas semanas, as histórias foram recolhidas e analisadas pelos dois professores, tendo em consideração os mesmos aspetos referidos anteriormente, tendo sido selecionadas oito histórias (aquelas que apresentavam maior número de ideias preconcebidas). Na aula seguinte, essas oito histórias foram distribuídas pelos alunos, que as analisaram em grupo (os alunos foram distribuídos em quatro grupos). Cada grupo selecionou uma história para ser apresentada ao resto da turma. Na última sessão, cada grupo promoveu e geriu uma discussão com toda a turma, acerca da história que escolheu. Neste caso, foram discutidas quatro histórias (uma selecionada por cada grupo) por toda a turma.

\section{Recolha e análise dos dados}

Com o objetivo de identificar as ideias dos alunos acerca da ciência e da atividade científica, as histórias escritas foram analisadas. Neste trabalho, foram analisadas todas as 28 histórias escritas pelos alunos do $9^{\circ}$ ano. No que diz respeito ao $11^{\circ}$ ano, foram apenas anali-

Ciênc. Educ., Bauru, v. 20, n. 1, p. 1-22, 2014 
sadas as quatro histórias que foram selecionadas para serem discutidas por toda a turma, devido ao seu grau de aprofundamento, uma vez que os alunos eram de um nível de escolaridade mais elevado. Assim, foi analisado um total de 32 histórias. Foi efetuada uma análise de conteúdo às histórias dos alunos, com base em categorias definidas na literatura, nomeadamente: a imagem global da ciência e os seus objetivos, as caraterísticas da atividade científica (local onde se desenvolve, métodos e instrumentos de pesquisa, construção do conhecimento científico) e as interações que a ciência estabelece com a sociedade (o impacto social da ciência e da tecnologia, o controlo efetuado pela sociedade, as relações entre os cientistas), refletidas pelas histórias (ver DRIVER et al., 1996; LEDERMAN, 2006; MCCOMAS, 1996, 1998).

Com o objetivo de conhecer as perceções dos alunos acerca da atividade, utilizamos uma abordagem distinta para as duas turmas em estudo. No caso do $9^{\circ}$ ano, foi aplicado um diferencial semântico (produzido no âmbito do projeto PARSEL), formado por 24 afirmações acerca de alguns aspetos cognitivos e afetivos relativos à atividade, nomeadamente: a sua contribuição na promoção do interesse e do gosto pela ciência, a sua relevância (sentido de propósito), a promoção da aprendizagem de conteúdo científico, a sua eficácia para a aprendizagem, e as dificuldades que os alunos sentiram. Em cada resposta, os alunos tiveram de escolher um valor, entre 1 e 5, no qual o valor 1 corresponde a "concordo completamente" e o valor 5 a "discordo completamente". No que diz respeito ao $11^{\circ}$ ano, um dos investigadores do presente artigo conduziu uma entrevista aberta, em grupo focado (com a duração de cerca de 1 hora), a um grupo de quatro alunos, selecionados aleatoriamente, com o objetivo de compreender a forma como estes vivenciaram a atividade e a avaliação que fizeram da mesma. Adicionalmente, dois alunos responderam a algumas questões online, acerca da popularidade, relevância, contribuição para a aprendizagem de conteúdos científicos, eficácia para a aprendizagem e dificuldades sentidas com a atividade. Para a análise destes dados, foi também efetuada a análise de conteúdo, com base em categorias previamente definidas: popularidade, relevância, contribuição para a aprendizagem de conteúdos científicos, eficácia para a aprendizagem e dificuldades sentidas.

Para a recolha de dados acerca do processo de implementação e as principais dificuldades sentidas pelos professores, os três professores foram entrevistados individualmente e foi realizada a análise de alguns documentos escritos, nomeadamente, as notas escritas pelos professores durante e após a implementação da atividade. Adicionalmente, um dos investigadores realizou observações naturalistas de duas sessões de discussão da turma do $11^{\circ}$ ano (de um total de quatro sessões, uma por cada grupo). As entrevistas, as notas dos professores e as notas do observador foram sujeitas a uma análise de conteúdo, com o objetivo de identificar a perceção dos professores acerca das potencialidades para a aprendizagem da atividade em análise e as principais dificuldades sentidas durante a sua implementação.

\section{Resultados e discussão}

Os resultados estão divididos em duas secções: numa primeira secção, apresentamos a visão sobre a atividade científica, sobre a natureza da ciência e do conhecimento científico, e sobre os cientistas que as histórias deixam transparecer, e discutimos esses resultados à luz da investigação. Numa segunda secção, exploramos o modo como foi conduzida a discussão na 
Faria, C. et al.

sala de aula, segundo a perspetiva tanto dos alunos como dos professores, refletindo sobre os seus limites e potencialidades.

\section{Análise das histórias}

\section{Visão global da ciência}

De uma maneira geral, as histórias analisadas, sejam do $9^{\circ}$ ou do $11^{\circ}$ ano, apresentam uma visão global da ciência e do papel dos cientistas muito positiva (esta visão positiva está presente em 14 histórias, dez histórias do $9^{\circ}$ ano e as quatro do $11^{\circ}$ ano). Como escreveu uma aluna do $9^{\circ}$ ano, "Podem dizer que, nós, cientistas pensamos de uma forma estranha, mas acreditem que é graças a nós que existe uma data de coisas!" ( $9^{\circ}$ ano). Uma outra aluna afirma que, "sem eles [os cientistas], o mundo não seria o mesmo". Um aluno descreve deste modo o cientista e a sua atividade, "[...] Voltámos às nossas pesquisas prontos para tentar descobrir novas coisas para haver uma vida melhor no nosso planeta" ( $9^{\circ}$ ano).

Nestas histórias é evidente o papel dos cientistas na criação de uma série de instrumentos e de condições que permitem melhorar a qualidade de vida da sociedade. De facto, muitos destes alunos equacionam a ciência como um meio de resolver alguns problemas maiores da sociedade (em particular, a cura de certas doenças). Uma história em quatro do $11^{\circ}$ ano e 12, em 28 histórias do $9^{\circ}$ ano, centram-se em tópicos relacionados com a cura de doenças (SIDA, cancro, malária, dengue); cinco histórias do $9^{\circ}$ ano focam-se no desenvolvimento de novas substâncias químicas, e três histórias do $11^{\circ}$ ano focam-se na pesquisa relacionada com a engenharia genética. Este caráter instrumental da ciência já tem sido apontado noutros estudos (ex. REIS; GALVÃO, 2006). Na sua revisão da literatura, Driver e colaboradores (1996, p. 49, tradução nossa) concluem que "a ciência é comumente vista de uma forma instrumental, como um meio de melhorar a condição humana, encontrando a cura para certas doenças e inventando novos dispositivos".

\section{Caraterísticas da atividade científica}

Um aspeto que sobressai nas histórias dos alunos é uma imagem não contextualizada da ciência (presente em 14 histórias do $9^{\circ}$ ano). Com efeito, as questões de investigação a que os cientistas, nas histórias criadas pelos alunos, têm que responder, parecem emergir de uma maneira óbvia da observação simples (Driver et al., 1996). Por exemplo, uma aluna descreve do seguinte modo a atividade dos cientistas:

"Era uma vez uma cientista, a Sara, que adorava inventar. Certo dia, ela acordou com a sensação de que precisava de inventar algo que marcasse. Então, ela, como não conhecia muitos cientistas, decidiu pôr um anúncio no jornal: "Procuram-se cientistas qualificados que tenham mente aberta e, já agora, que gostem de inventar [...]”. ( $9^{\circ}$ ano)

Ciênc. Educ., Bauru, v. 20, n. 1, p. 1-22, 2014 
Esta imagem da ciência é consistente com outros estudos (ex. WINDSCHITL; THOMPSON; BRAATEN, 2008), os quais têm revelado que quer os alunos, quer os professores de ciência reconhecem a atividade científica como um processo a-teórico, que emerge a partir de um vazio conceptual. Com efeito, neste trabalho, os alunos não parecem reconhecer a ideia de que a ciência é uma atividade social, que emerge num determinado contexto que influencia não só o modo como se faz a investigação, mas, também, o modo como os fenómenos são observados e interpretados e, mesmo, as questões que os cientistas colocam sobre o mundo natural. Contudo, é atualmente reconhecido que as crenças, os pressupostos teóricos, o conhecimento prévio, o treino, a experiência e as expetativas existentes criam um contexto que "afeta os problemas a ser investigados pelos cientistas, a forma como as suas investigações são desenvolvidas, aquilo que observam (e aquilo que não observam), e a forma como constroem um sentido, ou interpretam, essas mesmas observações" (LEDERMAN, 2006, p. 306).

Esta imagem não contextualizada e a-histórica da ciência reflete-se também nas estratégias utilizadas no decurso da atividade científica, que estão presentes nas histórias analisadas. Algumas das histórias dos alunos (cinco histórias do $9^{\circ}$ ano) representam cientistas a trabalhar segundo uma estratégia de "tentativa e erro" "“Os cientistas misturam as substâncias e veem o que acontece"), tal como ilustrado pelo seguinte exemplo.

“[...] começamos por misturar diferentes elementos, mas apenas conseguimos encontrar alguma coisa uma semana depois [...]. Quando finalmente encontramos a fórmula, fizemos vários testes para ver qual a reação que provocava [...]". ( $9^{\circ}$ ano)

"No laboratório, Atanásio disse: - Hey! Vamos juntar alguns elementos químicos.

Jervásio disse: - OK!

Ambos os cientistas aproximaram-se da mesa e misturaram "rabidlhegénio" com "puidlhemento", e após alguns anos a trabalhar na mistura conseguiram produzir "puidlheto de rabidhle".

Tó Zé disse: - Boa! Encontramos a cura para a SIDA!". (9ªno)

Muito provavelmente, estas imagens são construídas ao longo do percurso escolar dos alunos, durante o qual são levados a desenvolver experiências do tipo receitas, como vários estudos têm revelado (HOFSTEIN; LUNETTA, 2003; PEKMEZ; JOHNSON; GOTT, 2005;). Esta forma de fazer atividades experimentais, em que os alunos seguem um conjunto de passos predeterminados para obter resultados específicos, com vista a compreenderem de forma mais aprofundada determinados conceitos científicos, mas sem ser enquadrada num contexto mais amplo de como se chegou a esses dados e a essa questão (MCCOMAS, 1996; WINDSCHITL; THOMPSON; BRAATEN, 2008), leva a que os alunos repitam uma série de passos sem compreender o que estão a fazer e qual o propósito da atividade. Por exemplo, uma das histórias analisadas deixa transparecer de forma clara esta ausência de sentido na atividade experimental. 
Faria, C. et al.

"Ele estava acordado nessa manhã, obcecado pelo jogo que o mantinha acordado nesses últimos três dias. Entrou na sua sala um cientista que trazia um papel na mão, onde se lia: "Constant, temos que ir misturar elementos químicos até formarmos um novo elemento, se não vamos ser despedidos por não ter feito nada [...]".

"Se juntarmos Néon com Oxigénio e Ouro, se calhar, podemos conseguir. Rapidamente os quatro foram recolher todos os ingredientes necessários $[\ldots]$.

"No final, Jackson teve a ideia de juntar oxigénio com cobre, formando uma nova substância, a que deu o nome de Joades."- Acabamos!" Disse ele a todos, e saiu da sala". (9ªno)

De acordo com Windschtil, Thompson e Braaten (2008), os professores de ciências parecem ter apropriado uma determinada forma de entender a ciência e a construção do conhecimento científico, que lhes traz, em termos pedagógicos, claras vantagens. No entanto, esta forma de trabalhar a ciência faz com que os alunos "completem os aspetos técnicos de muitas das atividades de investigação sem compreenderem o conteúdo científico que lhes está subjacente, ou sem mesmo serem solicitados a raciocinar de forma científica" (WINDSCHTIL; THOMPSON; BRAATEN, 2008, p. 947, tradução nossa). Esta forma não contextualizada de pensar a ciência parece estar claramente refletida nalgumas das histórias dos alunos, tal como mostram os exemplos em cima, sendo necessário, tal como enfatizam Schwartz, Lederman e Crawford (2004), fazer compreender, aos alunos, a ideia de que a comunidade científica influencia, através das suas práticas e cultura, o que os cientistas estudam, bem como os processos que deverão seguir para conduzir uma investigação, para interpretar os dados, aceitar o conhecimento produzido e utilizá-lo.

Num outro sentido, importa também referir que, apesar desta visão a-teórica e ahistórica da ciência presente em muitas das histórias analisadas, em quatro das histórias (do $9^{\circ}$ ano), há, pelo contrário, referências claras à necessidade da realização de uma pesquisa prévia sobre a temática em investigação, de forma a contextualizar as questões de partida e as observações que irão nortear a investigação. Por exemplo, numa das histórias, e devido às dificuldades manifestadas pelos investigadores em descobrir novos elementos, o investigador responsável encorajou-os a procurar apoio na comunidade científica. Apresenta-se, a seguir, um excerto desse diálogo:

“[...] - Nos últimos dois dias tentamos diversos químicos e não descobrimos nada.

E já procuraram informação acerca do tema? Tentaram a Internet? Falaram com outras pessoas?!

Já tentamos nalguns livros, em enciclopédias e na Internet...mas ainda não falamos com ninguém. 
Bem, aconselho-vos a deixarem por um momento o laboratório e a procuraram outros cientistas e investigadores com quem possam falar. Quem sabe, se não vos podem ajudar". ( $9^{\circ}$ ano)

Um outro aspeto que sobressai nas histórias dos alunos prende-se com o local onde se desenvolve a atividade científica. Muitas das histórias (27 histórias, 23 histórias do $9^{\circ}$ ano e as quatro do $11^{\circ}$ ano), desenvolvem-se em redor de uma visão tradicional da atividade científica como uma atividade experimental, que, normalmente, decorre em laboratório. É revelador como um dos alunos (do $9^{\circ}$ ano) inicia a sua história: "Esta história mostra os cientistas a trabalhar no seu habitat natural... o laboratório" ( $9^{\circ}$ ano, grifo nosso). Os seguintes exemplos ilustram também a ideia do laboratório como o principal local onde se desenvolve a atividade científica:

"Hoje não aconteceu nada de extraordinário. Simplesmente, estivemos todo o dia no laboratório a fazer experiências". ( $9^{\circ}$ ano)

"A verdade é que de $2^{\mathrm{a}}$ a $6^{\mathrm{a}} \mathrm{f}$, a pesquisa dura $24 \mathrm{~h}$ sobre $24 \mathrm{~h}$. Há sempre alguém no laboratório, a fazer experiências". (11 ${ }^{\circ}$ ano)

Adicionalmente, para muitos destes alunos, a superioridade do conhecimento científico vem "do" método científico e da possibilidade de o conhecimento poder ser provado como sendo verdadeiro. Esta ideia é evidente em diversas histórias analisadas (16 histórias do $9^{\circ}$ ano). Por exemplo, uma aluna escreve como introdução à sua história:

"Acabámos de ser escolhidos de entre centenas de cientistas do mundo para tentar resolver um problema - a dengue. Eu, Richard Dawking, como líder desta investigação irei comandar os estudos. Resultados e conclusões serão retirados segundo o método científico". ( $9^{\circ}$ ano)

Como se "o" método científico, que a aluna entende como uma sequência linear de passos ("definição do problema, recolher de dados, proposta de uma hipótese, realização da experiência para testar a validade da hipótese, análise de resultados, interpretar dados e tirar conclusões" ( $9^{\circ}$ ano, grifo nosso) e que nos remete para uma imagem indutiva da ciência, fosse garantia da qualidade do conhecimento. Esta ideia de que a superioridade do conhecimento científico reside na possibilidade de ser provado, nomeadamente através da experimentação, está bastante generalizada no cidadão comum (MCCOMAS, 1996, 1998), apesar da questão da "prova" da validade do conhecimento colocar inúmeras dificuldades conceptuais (DRIVER et al., 1996; LEDERMAN, 2006; MCCOMAS, 1996, 1998). Tal como referido por Driver e colaboradores (1996, p. 44, tradução nossa, grifo dos autores):

[...] o conhecimento científico é o produto da comunidade, não do indivíduo. As descobertas relatadas por um indivíduo têm de vencer e ultrapassar os mecanismos de validação institucional, antes de serem aceites como conhecimento científico. 
Faria, C. et al.

Adicionalmente à ideia de que o conhecimento científico pode ser provado, e intimamente associado a ela, vem a ideia de que o conhecimento científico é absoluto e definitivo. Duas das histórias (do $9^{\circ}$ ano) refletem explicitamente esta noção ingénua, do conhecimento como algo absoluto e inquestionável:

"[...] Mas a ciência, para mim, tem de ser discutida, para que, em vez de termos várias conclusões, possamos chegar à conclusão correta”. ( $9^{\circ}$ ano, grifo nosso)

"O cientista é uma pessoa que defende acerrimamente a sua tese até conseguir provar aos outros que está totalmente certo [...]”. ( $9^{\circ}$ ano, grifo nosso)

A questão da imutabilidade e da inquestionabilidade do conhecimento construído parece estar associada, nestes alunos, à maior validade e, logo, ao maior reconhecimento deste tipo de conhecimento. Diversos autores têm alertado para o perigo que esta ideia apresenta. $\mathrm{Na}$ verdade, se esta ideia não for adequadamente desconstruída, poderá levar a uma visão negativa e desvalorizada do conhecimento produzido pelos cientistas (DRIVER et al., 1996; O’NEIL; POLMAN, 2004). A natureza provisória do conhecimento científico não depende apenas de este ser um tipo de conhecimento "inferencial, criativo, subjetivo, social e culturalmente embebido", tal como explica Lederman (2006, p. 307, tradução nossa), mas, também, de não poder ser provado. É, no entanto, essencial que os alunos compreendam que, independentemente da sua natureza provisória, o conhecimento científico é válido (AKERSON; VOLRICH, 2006), e que sejam capazes de associar a sua natureza provisória à sua generatividade, que permite sempre ir mais longe na compreensão dos fenómenos naturais. Por exemplo, Windschtil, Thompson e Braaten (2008, p. 948, tradução nossa) questionam "como pode o conhecimento ser visto como um catalisador de novas ideias, se este for visto apenas como um produto final da investigação?". É, no entanto, de referir que este caráter provisório emerge nas histórias de alguns alunos (quatro histórias do $9^{\circ}$ ano). Por exemplo, um aluno do $9^{\circ}$ ano termina a sua história da seguinte forma:

"O trabalho de um cientista nunca termina, apenas evolui. Os cientistas trabalham numa pesquisa, mas cada conclusão a que chegam não leva apenas a uma resposta, leva também a outro problema". ( $9^{\circ}$ ano)

\section{Ciência versus sociedade}

Duas outras dimensões da ciência que sobressaem nas histórias analisadas são as questões éticas e as relações da comunidade científica. A dimensão ética da atividade científica está claramente presente nas histórias analisadas do $11^{\circ}$ ano. Pelo contrário, estes aspetos não são mencionados em nenhuma das 28 histórias do $9^{\circ}$ ano. É no entanto de referir que, no caso dos alunos do $11^{\circ}$ ano, este trabalho foi realizado em conjunto com o professor de filosofia, com quem este tipo de questões é usualmente explorado. As histórias analisadas refletiram preocupações acerca dos limites éticos da ciência: investigação científica sim, mas até onde

Ciênc. Educ., Bauru, v. 20, n. 1, p. 1-22, 2014 
podemos ir com a investigação tendo em atenção os seus propósitos e as condições em que se desenvolve? Por exemplo, um aluno escreveu:

"A Ana disse que a sua maior dificuldade durante a sua formação foi submeter os animais a essas experiências. Quando ela era aluna da faculdade, teve uma grande discussão com o seu professor acerca da questão de ser ou não moralmente aceitável submeter os animais à experimentação. Se os sujeitos das experiências fossem humanos, seriam estas experiências aceites pela sociedade?”. (11 ano)

Outro aluno terminou a sua história da seguinte forma:

"[...] mas eu acredito que, com todo o progresso científico que tem ocorrido nos últimos anos, e independentemente das questões éticas e morais envolvidas, a criação deste ser irá ocor rer em breve". (11ªno)

No que diz respeito às relações da comunidade científica, Sharkway (2009) refere a existência de um contexto social interno (que envolve as interações dentro da comunidade científica) e uma dimensão externa (que envolve as interações que os cientistas estabelecem com o público leigo). Ambas as dimensões referidas estavam presentes nas histórias analisadas neste trabalho. De facto, muitos alunos (em 11 histórias, nove do $9^{\circ}$ ano e duas do $11^{\circ}$ ano) mencionaram o papel que a comunidade científica desempenha na partilha de informação e de recursos para o apoio a outras investigações (contexto social interno), tal como ilustrado no exemplo seguinte:

"Na Europa, havia muitos cientistas a trabalhar no mesmo tema [...]. Tal como combinado, no dia seguinte, o Rui lançou um apelo na Internet. $[\ldots]$ E depois, felizmente, uma pessoa leu o seu apelo! No ano passado, um grupo de Chineses conseguiu encontrar a combinação correta para curar pessoas com o mesmo tipo de sangue da Eva. Mas como não conseguiram curar pessoas com outros tipos de sangue, eles não conseguiram obter dinheiro para continuar a sua investigação e desistiram. Mas agora, era altura de ambas as equipas poderem triunfar". (11 ${ }^{\circ}$ ano, grifo nosso)

Em relação às interações entre os cientistas e o público leigo ou a sociedade (contexto social externo), as histórias do $11^{\circ}$ ano analisadas mostram uma grande ênfase na existência de uma relação bilateral. As quatro histórias analisadas enfatizam a ideia de que a ciência não resolve apenas problemas sociais, como, também, cria outros problemas, que se encontram fora do âmbito da atividade científica per si, e em relação aos quais o público tem alguma intervenção. No exemplo apresentado, o poder político interferiu com a atividade científica, através do não-financiamento da continuação das pesquisas.

Pelo contrário, as histórias do $9^{\circ}$ ano analisadas não apresentam qualquer referência a esta relação biunívoca entre a ciência e a sociedade, enfatizando apenas uma relação unidireci- 
Faria, C. et al.

onal (presente em 13 histórias do $9^{\circ}$ ano), i.e. o impacto das descobertas científicas na sociedade, mas não o contrário:

"No dia seguinte chegamos a Portugal e toda a gente queria encontrarse connosco e pedir-nos um autógrafo. Disseram-nos que a nossa descoberta iria ser transmitida por todos os canais [de TV] do mundo inteiro $[\ldots]^{\prime \prime} .\left(9^{\circ}\right.$ ano $)$

"No dia seguinte, depois de ter aparecido a notícia nos jornais de que a equipa era responsável pela descoberta da cura dessa doença [...], o grupo voltou para o trabalho, ansioso e entusiasmado, e, simultaneamente, sentindo-se altamente responsável pois sabiam que toda a gente tinha grandes expetativas acerca deles e acerca da possibilidade de encontrarem a cura para a doença". ( $9^{\circ}$ ano)

\section{Avaliação da atividade: apreciação geral e dificuldades na implementação}

Os alunos, no geral, fizeram uma apreciação muito positiva, referindo que gostaram bastante de participar na atividade. A análise dos resultados do diferencial semântico revela que a maioria dos alunos do $9^{\circ}$ ano concorda com a afirmação de que a atividade foi interessante (média $=2.26$, intervalo: $1-4)$ e agradável (média $=1.63$, intervalo: $1-3$ ). Além disso, consideraram que a atividade promoveu a sua participação (média $=1.63$, intervalo: $1-5$ ) e que lhes permitiu a partilha de ideias e opiniões (média $=2.17$, intervalo: $1-3$ ). O professor do $9^{\circ}$ ano concorda que os alunos se envolveram com a atividade, referindo:

"Até a própria motivação para eles fazerem as histórias foi engraçada. Houve uns que ficaram bloqueados. "Mas eu não vou conseguir escrever nada". "Começas a escrever e vais por aî". E, portanto, toda a gente participou. Não houve nenhum aluno que não fizesse a história. E depois foi muito bom, porque, no fim, achei que na discussão final estavam empenhados em participar. E eu acho que isso foi muito bom". (Professor do $9^{\circ}$ ano)

As razões para a apreciação positiva dos alunos do $11^{\circ}$ são de dois tipos: a natureza da atividade (uma atividade de escrita, de que eles gostam particularmente); e o grau de abertura da atividade (visto a escrita acerca de um determinado tópico apelar para uma grande criatividade). De acordo com um dos alunos, "Nós pudemos utilizar a nossa imaginação". No entanto, apesar da apreciação positiva, os alunos do $11^{\circ}$ ano poderão não ter compreendido o objetivo principal da atividade. $\mathrm{Na}$ entrevista, os alunos questionaram a sua relevância e salientaram que não tinham aprendido muito no que se refere à aquisição de conhecimento científico. Segundo a sua perspetiva, eles apenas aprenderam conhecimentos relacionados com o 
tópico da sua própria história, no decorrer da pesquisa que realizaram para a sua escrita. Os comentários escritos também traduzem esta perspetiva:

"Penso que neste módulo não aprendi muito porque a minha história estava bastante ficcionada. Só algumas caraterísticas importantes sobre alguns animais que usei na história". (11ªno)

"Apreendi mais sobre como são regulados alguns sistemas relacionados com a ciência como por exemplo as vacinas. Também percebi melhor alguns problemas depois da sua interpretação filosófica. Mesmo assim penso que não aprendi muita coisa". (11 ano)

A análise do questionário aplicado aos alunos do $9^{\circ}$ ano também revelou que o principal objetivo da atividade, i.e. a promoção de uma melhor compreensão acerca da NC, não terá sido atingido. $\mathrm{Na}$ verdade, os alunos não concordaram com a afirmação de que a atividade tenha contribuído para promover a sua compreensão acerca da NC (média $=2.84$, intervalo: 1-5). Estes resultados poderão estar relacionados com alguns aspetos que poderão não ter decorrido da melhor forma: feedback ineficaz, má organização e gestão da discussão, dificuldades na transposição do conhecimento acerca da NC para as práticas de sala de aula. No caso dos alunos do $9^{\circ}$ ano, o feedback dado durante a atividade de discussão poderá não ter sido o mais adequado, visto terem considerado que o feedback do professor não foi importante (média $=3.26$; intervalo: $1-5$ ) e que a atividade não permitiu um bom acompanhamento por parte do professor (média $=3.21$; intervalo: $1-5$ ). $\mathrm{O}$ facto de não termos inquirido diretamente os alunos limita-nos na nossa análise: o que significa não ser importante o feedback do professor? Significa que não deu feedback ou que este não foi relevante? E se foi este o caso, por que não foi relevante? Quais eram as expetativas dos alunos? E o que quer dizer não ter havido uma boa monitorização por parte do professor?

No entanto, embora não tenhamos dados dos alunos, a entrevista realizada ao professor do $9^{\circ}$ ano dá-nos conta de algumas dificuldades, nomeadamente no confronto das ideias estereotipadas dos alunos e, mesmo, em torná-las suficientemente explícitas para permitir a sua discussão. De acordo com o professor, "Eu fiz uma síntese do que eram os mitos [ideias estereotipadas], mas acho que foi difícil compreenderem, aplicarem o mito àquela história. Lá está, foi a minha maior dificuldade" (Professor do $9^{\circ}$ ano). Este professor também indica, como uma grande barreira à implementação da atividade, o tempo que demorou a desconstruir as histórias. Tal como explica,

"E foi aquele com o qual eu tive mais dificuldade em lidar, porque... se calhar não me apercebi muito bem, mas eu fiz uma análise exaustiva de todas as histórias. Demorei imenso tempo, muito mais do que uma semana a ver aquilo tudo. Porque tinha que estar com a grelha [com as categorias de análise], depois ele dizia isto e depois dizia aquilo". (Professor do $9^{\circ}$ ano) 
Faria, C. et al.

Contudo, ao contrário da perspectiva dos alunos, este professor considera que eles aprenderam, que compreenderam as finalidades da ciência. Segundo palavras suas,

"Mas acho que no fim, na discussão final eu acho que eles se aperceberam... Porque eu estou sempre a trabalhar com eles a parte dinâmica, de construção de ciência. E acho que, no fim, eles se aperceberam qual era a finalidade. [...] Porque eles têm ideia da bata branca. É o laboratório. E, portanto, o desmistificar de alguns mitos, acho que ficou muito claro, mais claro para eles qual era a finalidade das ciências [...] O desmistificar da história foi muito bom, porque mostrou que há imensa gente que pensa da mesma maneira que eles. E coisas erradas, que eles depois perceberam que são mitos e que são partilhados por vários e nós tentámos desmistificar". (Professor do $9^{\circ}$ ano)

No que diz respeito à implementação da atividade de discussão no $11^{\circ}$ ano, a observação das sessões de discussão permitiu compreender outras dificuldades. Apesar de no início das discussões, os alunos tentarem levantar algumas questões e iniciar o debate, relacionado com os aspetos controversos presentes nas histórias (ex. experimentação animal), as discussões limitaram-se a ideias do senso comum, sem qualquer fundamentação científica. Estes resultados não são novos. Por exemplo, Walker e Zeidler (2007, p. 1403, tradução nossa) observaram, no seu estudo, que "os alunos utilizam o aspeto mais factual das evidências, o que em última instância os conduz a um raciocínio falacioso e a ataques pessoais", não avançando na sua reflexão acerca da natureza do conhecimento científico e não utilizando esse conhecimento para a avaliação dos pressupostos científicos. Tendo em conta estes resultados, estes autores realçam o papel fundamental que o professor terá de ter no suporte destas discussões. No mesmo sentido, Osborne e colaboradores (2003, p. 716, tradução nossa) enfatizam a necessidade de "haver uma mediação atenta da parte do professor no decorrer das aulas, para salientar, de forma explícita, as caraterísticas processuais da atividade científica”, para que os alunos sejam capazes de criar uma imagem da ciência mais real e precisa. Não se trata apenas de tornar visíveis alguns aspetos acerca da NC, mas também de estabelecer ligações entre as situações de aprendizagem (ex. as imagens dos alunos acerca da ciência) e o trabalho dos cientistas (AKERSON; VOLRICH, 2006; SHARKWAY, 2009).

Neste trabalho, e com base nas observações das situações de discussão, verificou-se que o professor desempenhou um papel extremamente passivo, nunca contribuindo para a discussão geral, tendo sido dada muito pouca orientação para a gestão da discussão, mesmo quando os alunos revelavam algumas dificuldades. Por exemplo, a certa altura, na discussão, um aluno questionava: "Mas quais são os princípios da ciência?" (Notas de campo). Este aspeto não foi sequer identificado ou reconhecido como sendo importante pelo professor, e o debate retrocedeu para a discussão de ideias vagas e pouco fundamentadas cientificamente. Este sentimento de "falta de rumo" na discussão reflete-se nas notas de campo.

“[...] O Professor de Filosofia em nenhuma ocasião pegou nos "falsos" conhecimentos dos alunos, para debater, por exemplo, a questão do conhecimento científico versus senso-comum (aspeto abordado nas 
aulas de filosofia, mas se discutido neste contexto poderia adquirir um outro sentido e relevância para os alunos). No fim da aula, o professor comentou comigo as apresentações dos alunos e uma das críticas que apontou foi que, muito embora, um dos grupos tenha apresentado como aspeto central para debater - a relação entre ficção científica e ciência, e ciência e suas aplicações na sociedade, esse grupo não desenvolveu essa ideia. Ora, se calhar, o professor não deveria ter deixado cair essa questão, como o fez, ainda mais quando diz, no final, que a considera fundamental. Parece, pois, que a finalidade da atividade deveria ser mais clara para os professores e que eles deveriam ter um conjunto de questões mais explícitas para orientar a discussão". (Notas de campo)

Um dos professores referiu durante a entrevista, "Eu senti que não tinha nada a que me agarrar. Senti que esta coisa de 'trabalho de um cientista' é muito vago, [...] tem muitas implicações" (professor de Biologia do $11^{\circ}$ ano).

Os professores envolvidos neste trabalho tinham a intenção de explorar a NC nas suas aulas, de forma a conseguirem ultrapassar determinadas ideias inadequadas dos alunos acerca da ciência. No entanto, não foram bem-sucedidos na transposição dessas temáticas para as suas práticas de sala de aula, uma dificuldade já apontada por Akerson e Volrich (2006). Alguns estudos têm revelado a falta de conhecimento pedagógico e epistemológico, por parte dos professores, para a promoção e gestão de discussões acerca da NC (MCCOMAS, 1998; WINDSCHITL; THOMPSON; BRAATEN, 2008), assim como a prevalência de conceções ingénuas acerca da NC, que não facilitam o confronto e discussão das ideias apresentadas pelos alunos (WINDSCHITL; THOMPSON; BRAATEN, 2008). Um conhecimento didático deficiente (GESS-NEWSOME, 2002; SHULMAN, 1986), que se reflete na falta de competências para a gestão da discussão como uma ferramenta pedagógica (PARKER; HESS, 2001), associada à complexidade da própria tarefa, poderá, pois, explicar as dificuldades observadas nos professores envolvidos.

\section{Considerações finais}

Neste trabalho, a atividade de escrita revelou-se como um instrumento eficaz para aceder às ideias dos alunos acerca dos cientistas e da atividade científica. A análise das histórias imaginadas, escritas pelos alunos, revelou um elevado número de ideias estereotipadas acerca dos cientistas e do seu trabalho, nomeadamente: uma visão geral da ciência como um meio de resolver os maiores problemas da sociedade, sem qualquer referência aos problemas que pode causar; uma visão da atividade científica como estando totalmente isolada do contexto social, político e tecnológico da época, e a noção do conhecimento científico como algo absoluto e inquestionável.

De acordo com diversos estudos, muitas destas ideias estereotipadas podem ser derivadas dos meios de comunicação social (ex.: filmes, televisão, e livros de banda desenhada) (ex.: DRIVER et al., 1996; FINSON, 2002; MATTHEWS; DAVIES, 1999; REIS; GALVÃO, 
2004, 2006, 2007). Pekmez, Johnson e Gott (2005) sugeriram, como outra possível fonte de estereótipos, nomeadamente aqueles relacionados com os processos científicos, o próprio trabalho desenvolvido na escola, nas aulas de ciências. As atividades experimentais que são desenvolvidas em sala de aula tendem, muitas vezes, a ser meras receitas a serem seguidas pelos alunos, de uma forma totalmente descontextualizada e sem um propósito aparente (HOFSTEIN; LUNETTA, 2003).

A questão-chave é como lidar com estas duas forças: as práticas de sala de aula, e as imagens transmitidas pelos meios de comunicação social. A investigação aponta para a importância de confrontar e clarificar, de forma explícita, estas imagens estereotipadas acerca da ciência e da atividade científica, de forma a aprofundar a compreensão dos alunos acerca da NC (LEDERMAN, 2006; SCHWARTZ; LEDERMAN; CRAWFORD, 2004). Para atingir este objetivo, os professores terão de ser capazes de desenvolver formas efetivas de identificar e de discutir as ideias dos alunos (FINSON, 2002). As histórias acerca de cientistas e do seu trabalho podem funcionar como uma ferramenta útil para atingir esse objetivo, tal como revelado neste trabalho. No entanto, para a promoção de uma alteração efetiva dessas ideias, os alunos terão de se envolver na discussão acerca das mesmas (AKERSON; VOLRICH, 2006). $\mathrm{Na}$ mesma linha, refere Ribeiro e Martins (2007) que as narrativas sobre descobertas científicas e cientistas podem constituir pontos de partida fundamentais para se discutirem aspetos relacionados com a natureza da ciência e com a atividade científica; mas chama a atenção para a importância do papel mediador do professor nesse processo.

No presente estudo, a promoção e gestão das sessões de discussão provou ser uma tarefa difícil tanto para os alunos, como para os professores. Os alunos não mobilizaram qualquer conhecimento científico para fundamentar as suas opiniões acerca da $\mathrm{NC}$ e, aparentemente, não perceberam qual o propósito da sessão de discussão; os professores revelaram algumas dificuldades em desconstruir as preconceções dos alunos e em gerir as sessões de discussão de uma forma proveitosa para os mesmos.

Tendo em conta estas dificuldades, sugerimos que a discussão deva ser integrada num contexto de trabalho, no qual os alunos sejam encorajados a estabelecer ligações com o trabalho de cientistas reais e a concretizar os processos envolvidos na construção do conhecimento científico. Por exemplo, alguns autores sugeriram que a discussão de alguns programas de televisão e de filmes, na qual se procura ajudar os alunos a identificar ideias estereotipadas, e o contacto com cientistas, dentro e fora da sala de aula, através de atividades de natureza investigativa e de resolução de problemas, são estratégias passíveis de ajudar os professores na sua tarefa de desconstrução destas ideias estereotipadas (FINSON, 2002; LEDERMAN, 2006). Adicionalmente a estas propostas, sugerimos a inserção deste tipo de atividades em contextos museológicos. De facto, os museus de ciência possuem recursos únicos, tais como as coleções históricas e documentos acerca de cientistas reais e da atividade que desenvolveram. Estes locais podem constituir-se como contextos reais e concretos que poderão facilitar o contacto dos alunos com os processos associados à atividade científica (FALK; DIERKING, 2000). Faria, Pereira e Chagas (2012), num estudo acerca dos impactos da inserção da história da ciência no ensino da ciência, evidenciaram que o envolvimento dos alunos em atividades inseridas num museu de ciência, relacionadas com a história da ciência, pode constituir um contexto estimulante para o aprofundamento da compreensão acerca das práticas científicas ao longo do tempo. Este contexto (museológico) poderá servir de cenário, no qual as ideias 
"Como trabalham os cientistas?" ...

reveladas pelos alunos nas histórias sejam testadas e confrontadas com processos e histórias reais. $\mathrm{Na}$ verdade, a construção de situações de aprendizagem, nas quais os alunos possam lidar com documentos históricos reais e histórias de cientistas do passado, e possam confrontar as suas conceções com eventos históricos reais, pode ajudar os professores na tarefa de promover, nos alunos, uma perspetiva da ciência como um empreendimento humano, que emerge dum contexto social, político e histórico específico. A ligação a museus e centros de ciência pode igualmente favorecer uma mudança nas conceções dos professores sobre a NC, já que constituem "oportunidades para a reflexão didática e pedagógica" (CHINELLI; FERREIRA; AGUIAR, 2010, p. 33), fundamental para o desenvolvimento de práticas de sala de aula que favoreçam a aprendizagem e a reflexão dos alunos sobre a ciência e a natureza da atividade científica.

\section{Agradecimentos}

Parte deste estudo foi financiado pela Comissão Europeia ( $\left.6^{\circ} \mathrm{FWP}\right)$, como sendo parte de um projeto Europeu PARSEL - Popularity and Relevance of Science Education for Scientific Literacy.

\section{Referências}

AKERSON, V. L.; ABD-EL-KHALICK, F. S. "How should I know what scientists do - I am just a kid": fourth grade students' conceptions of nature of science. Journal of Elementary Science Education, Bradley, v.17, n. 1, p. 1-11, 2005. Disponível em: <http://link.springer.com/article/10.1007\%2FBF03174669>. Acesso em: 31 jan. 2014.

AKERSON, V. L.; VOLRICH, M. Teaching nature of science explicitly in a first grade internship setting. Journal of Research in Science Teaching, Hoboken, v. 43, n. 4, p. 377-394, 2006.

CHINELLI, M. V., FERREIRA, M. V. S.; AGUIAR, L. E. V. Epistemologia em sala de aula: a natureza da ciência e da atividade científica na prática profissional de professores de ciências. Ciência \& Educação, Bauru, v. 16, n. 1, p. 17-35, 2010. Disponível em: <http://www.scielo.br/pdf/ciedu/v16n1/v16n1a02.pdf >. Acesso em: 31 jan. 2014.

DAWSON, V. M.; VENVILLE, G. Teaching strategies for developing students' argumentation skills about socioscientific issues in high school genetics. Research in Science Education, Dordrecht, v. 40, n. 2, p. 133-148, 2010.

DAY, S. P.; BRYCE, T. G. K. Does the discussion of socio scientific issues require a paradigm shift in science teachers' thinking? International Journal of Science Education, Abingdon, v. 33, n. 12, p. 1675-1702, 2011.

DOISE, W.; MUGNY, G.; PERRET-CLERMONT, A-N. Social interaction and the development of cognitive operations. European Journal of Social Psychology, Bognor Regis, v. 5, n. 3, p. 367-383, 1975. 
Faria, C. et al.

DRIVER, R. et al. Young people's images of science. Buckingham: Open University Press, 1996.

DUSCHL, R. Relating history of science to learning and teaching science: using and abusing. In: FLICK, L. B.; LEDERMAN, N. G. (Ed.). Scientific inquiry and nature of science: implications for teaching, learning, and teacher education. New York: Springer, 2006. p. 319-330.

DUSCHL, R.; GRANDY, R. (Ed.). Teaching scientific inquiry: recommendations for research and implementation. Rotterdam: Sense Publishers, 2008.

ERICKSON, F. Qualitative methods in research on teaching. In: WITTROCK, M. C. (Ed.). Handbook of research on teaching. 3. ed. New York: Macmillan, 1986. p. 3-36.

FALK, J. H.; DIERKING, L. D. Learning from museums: visitors experiences and their making of meaning. Walnut Creek: Altamira Press, 2000.

FARIA, C.; PEREIRA, G.; CHAGAS, I. D. Carlos de Bragança, a pioneer of experimental marine oceanography: filling the gap between formal and informal science education.

Science \& Education, Heidelberg, v. 21, n. 6, p. 813-826, 2012.

FINSON, K. D. Drawing a scientist: what we do and do not know after fifty years of drawings. School Science and Mathematics, Cincinnati, v. 102, n. 7, p. 335-345, 2002.

GESS-NEWSOME, J. Pedagogical content knowledge: an introduction and orientation. In: GESS-NEWSOME, J.; LEDERMAN, N. G. (Ed.). Examining pedagogical content knowledge. New York: Springer, 2002. p. 3-17.

HOFSTEIN, A.; LUNETTA, V. N. The laboratory in science education: foundations for the twenty-first century. Science Education, Hoboken, v. 88, n. 1, p. 28-54, 2003.

KHISHFE, R.; ABD-EL-KHALICK, F. S. Influence of explicit and reflective versus implicit inquiry-oriented instruction on sixth graders' views of nature of science. Journal of Research in Science Teaching, Hoboken, v. 39, n. 7, p. 551-578, 2002.

LEDERMAN, N. G. Syntax of nature of science within inquiry and science instruction. In: FLICK, L. B.; LEDERMAN, N. G. (Ed.). Scientific inquiry and nature of science. Dordrecht: Springer, 2006. p. 301-318

MATTHEWS, B.; DAVIES, D. Changing children's images of scientists: can teachers make a difference? School Science Review, Hatfield, v. 80, n. 293, p. 79-85, 1999.

MCCOMAS, W. F. The principal elements of the nature of science: dispelling the myths. In:__ (Ed.). The nature of science in science education: rationales and strategies. Dordrecht: Kluwer, 1998. p. 3-39.

MCCOMAS, W. F. Ten myths of science: reexamining what we think we know.... School Science and Mathematics, Cincinnati, v. 96, n. 1, p. 10-16, 1996.

O'NEIL, D. K.; POLMAN, J. L. Why educate little scientists? Examining the potential of practice-based scientific literacy. Journal of Research in Science Teaching, Hoboken, v. 41, n. 3, p. 234-266, 2004. 
"Como trabalham os cientistas?" ...

OSBORNE, J.; ERDURAN, S.; SIMON, S. Enhancing the quality of argumentation in school science. Journal of Research in Science Teaching, Hoboken, v. 41, n. 10, p. 994-1020, 2004.

OSBORNE, J. et al. What ideas-about-science should be taught in school science? A Delphi study of the expert community. Journal of Research in Science Teaching, Hoboken, v. 40, n. 7 , p. $692-720,2003$.

PARKER, W. C.; HESS, D. Teaching with and for discussion. Teaching and Teacher Education, Edmonton, v. 17, p. 273-289, 2001.

PEKMEZ, E. S.; JOHNSON, P.; GOTT, R. Teachers' understanding of the nature and purpose of practical work. Research in Science \& Technological Education, Nottingham, v. 23, n. 1, p. 3-23, 2005.

PORTUGAL. Ministério da Educação. Reforma do Ensino Secundário. Documento orientador da revisão curricular ensino secundário. Lisboa, 2003.

PORTUGAL. Ministério da Educação. Departamento da Educação Básica. Orientações curriculares para as ciências físicas e naturais do $3^{\circ}$ ciclo do ensino básico. Lisboa, 2001.

PRAIA, J.; GIL-PÉREZ, D.; VILCHES, A. O papel da natureza da ciência na educação para a cidadania. Ciência \& Educação, Bauru, v. 13, n. 2, p. 141-156, 2007. Disponível em: <http://www.scielo.br/pdf/ciedu/v13n2/v13n2a01.pdf>. Acesso em: 31 jan. 2014.

REIS, P.; GALVÃO, C. O diagnóstico de concepções sobre os cientistas através da análise e discussão de histórias de ficção científica redigidas pelos alunos. Revista Electrónica de Enseñanza de las Ciencias, Vigo, v. 5, n. 2, p. 213-234, 2006.

REIS, P.; GALVÃO, C. Reflecting on scientists' activity based on science fiction stories written by secondary students. International Journal of Science Education, Abingdon, v. 10, n. 6, p. 1245-1260, 2007.

REIS, P.; GALVÃO, C. Socio-scientific controversies and students' conceptions about scientists. International Journal of Science Education, Abingdon, v. 26, n. 13, p. 1621-1633, 2004.

REIS, P.; RODRIGUES, S.; SANTOS, F. Concepções sobre os cientistas em alunos do $1^{\circ}$ ciclo do ensino básico: "poções, máquinas, monstros, invenções e outras coisas malucas". Revista Electrónica de Enseñanza de las Ciencias, Vigo, v. 5, n. 1, p. 51-74, 2006.

RIBEIRO, R. M. L.; MARTINS, I. O potencial das narrativas como recurso para o ensino de ciências: uma análise em livros didáticos de física. Ciência \& Educação, Bauru, v. 13, n. 3, p. 293-309, 2007. Disponível em: <http://www.scielo.br/pdf/ciedu/v13n3/ a02v13n3.pdf>. Acesso em: 31 jan. 2014.

SADLER, T.; ZEIDLER, D. The significance of content knowledge for informal reasoning regarding socioscientific issues: applying genetics knowledge to genetic engineering issues.

Science Education, Hoboken, v. 89, n. 1, p. 71-93, 2005. 
Faria, C. et al.

SCHWARTZ, R. S.; LEDERMAN, N. G.; CRAWFORD, B. A. Developing views of nature of science in an authentic context: An explicit approach to bridging the gap between nature of science and scientific inquiry. Science Education, Hoboken, v. 88, n. 4, p. 610645, 2004.

SHARKWAY, A. Moving beyond the lone scientist: helping 1st-grade students appreciate the social context of scientific work using stories about scientists. Journal of Elementary Science Education, Bradley, v. 2, n. 1, p. 67-78, 2009.

SHULMAN, L. S. Paradigms and research programs in the study of teaching. In:

WITTROCK, M. C. (Ed.). Handbook of research on teaching. New York: MacMillan, 1986. p. $432-463$

SIMON, S.; ERDURAN, S.; OSBORNE, J. Learning to teach argumentation: research and development in the science classroom. International Journal of Science Education, Abingdon, v. 28, n. 2-3, p. 235-260, 2006.

TEIXEIRA, E. S.; FREIRE JR., O.; EL-HANI, C. N. A influência de uma abordagem contextual sobre as concepções acerca da natureza da ciência de estudantes de física.

Ciência \& Educação, Bauru, v. 15, n. 3, p. 529-556, 2009. Disponível em:

<http://www.scielo.br/pdf/ciedu/v15n3/06.pdf>. Acesso em: 31 jan. 2014.

WALKER, K.A.; ZEIDLER, D.L. Promoting discourse about socioscientific issues through scaffolded inquiry. International Journal of Science Education, Abingdon, v. 29, n. 11, p. 1387-1410, 2007.

WINDSCHITL, M.; THOMPSON, J.; BRAATEN, M. Beyond the scientific method: model-based inquiry as a new paradigm of preference for school science investigations. Science Education, Hoboken, v. 92, n. 5, p. 941-967, 2008.

Artigo recebido em 25/04/13. Aceito em 18/12/13. 